кандидат экономических наук, доцент, доцент кафедры «Финансы и кредит» Южного федерального университета

Кириченко Марина Валерьевна

кандидат экономических наук, доцент кафедры «Финансы и кредит» Южного федерального университета

\section{УСТОЙЧИВОСТЬ ФИНАНСОВОЙ СИСТЕМЫ РЕГИОНА: СУЩНОСТЬ, ФАКТОРЫ, ИНДИКАТОРЫ}

\begin{abstract}
Аннотация:
В статье раскрывается сущность категории "устойчивость финансовой системы региона», выявлены ее отличительные признаки как интегрального свойства устойчивого развития региональной финансовой системы во взаимосвязи с экономическим ростом региона. Систематизиро ваны и саруппированы факторы, влияющие на устойчивость региональной финансовой системы. Обоснованы базовые критерии и показатели оценки, которые отражают инвестиционные и социально-экономические эффекты взаимодействия с региональной экономикой.
\end{abstract}

Ключевые слова:

финансовая система региона, устойчивое развитие, фокторы, критерии, индикаторы, региональная экономика.
PhD in Economics, Assistant Professor, Finance and Credit Department, Southern Federal University

Kirichenko Marina Valeryevna

PhD in Economics, Assistant Professor, Finance and Credit Department, Southern Federal University

\section{THE STABILITY OF THE FINANCIAL SYSTEM OF THE REGION: ESSENCE, FACTORS, INDICATORS}

Summary

The article provides insight into the category of "stability of the financial system of the region" and identifies its distinctive features as an integral property of the sustainable development of the regional financial system in conjunction with the economic growth of the region. The authors systematize and group the factors af fecting the stability of the regional financial system. The study proves the basic criteria and the evaluation indicators which reflect the investment and social and economic effects of interaction with the regional economy.

Keywords: financial system of the region, sustainable development, factors, criteria, indicators, regional economy.

Одним из качественных свойств финансовой системы страны и регионов является устойчивость, которая в общем плане трактуется как способность системы сохранять структуру под воздействием возмущающих фракторов или возвращаться в прежнее состояние после нарушения.

Исследование устойчивости различных экономических объектов и систем, формирование устойчивой модели развития российской экономики является достаточно «модным» научным направлением. Десятки научных публикаций посвящены теоретическим и практическим аспектам этой проблемы. Наиболее пристальное внимание специалистов фокусируется на фринансовой составляющей устойчивости экономических систем. И это не случайно, так как в современных условиях фринансовая глобализация привела к появлению новых угроз и вызовов российской экономике, в том числе и ее финансовой системе. Активная научная разработка вопросов фринансовой устойчивости сложных экономических объектов - предприятий, организаций, компаний, отраслей и секторов экономики, регионов и национальной экономики в целом - нацелена на укрепление финансовой безопасности страны.

Предметом исследования является устойчивость финансовой системы региона. Теоретический анализ показал, что не сложилось единого, достаточно обоснованного и согласованного представления о базовых понятиях подобных исследований. Нет ответа на вопрос: эквивалентны ли понятия «финансовая устойчивость региона» и «устойчивость финансовой системы региона»? Нередко эти понятия употребляются как тождественные и между ними не проводится существенного различия.

Преимущественно исследуется категория ффинансовой устойчивости национальной экономики или устойчивости региона с целью поиска критериев и показателей оценки устойчивости, выявления рисков и определения направлений повышения устойчивости региона или его отдельных подсистем. Чаще всего это банковский сектор или региональные и муниципальные финансы [1]

Категория устойчивости финансовой системы (страны, региона) разработана в меньшей степени. На это обращает внимание в своей статье ректор Финансового университета при Правительстве Российской Федерации М.А. Эскиндаров. Он отмечает, что используемые в зарубежной и российской практике методики оценки устойчивости финансовой системы неоднородны и 
в основном ориентированы на анализ финансовой устойчивости. Каждая из них носит узкую целевую направленность: в лучшем случае рассматривается оценка отдельных подсистем фринансовой системы, отдельных рынков, институтов финансовой системы [2, с. 18].

Цели работы - раскрыть сущность категории «устойчивость финансовой системы региона», ее отличительные признаки как интегрального свойства финансовой системы во взаимосвязи с экономическим ростом и развитием региона; выявить факторы, влияющие на устойчивость региональной финансовой системы; обосновать критерии и показатели оценки.

Теоретическую основу составляют исследования, в которых выполнен содержательный анализ понятий: «финансовая система региона» и фракторы ее развития, «финансовая устойчивость региона», «экономическая безопасность региона», «устойчивость экономических систем». Обоснование критериев оценки уровня устойчивости финансовой системы региона строилось в соответствии с концептуальным подходом к показателям, характеризующим устойчивость сложных экономических объектов, разработанным в Международном институте устойчивого развития. Применялись методы системного подхода, логического, сравнительного и структурно-функционального анализа.

Сравнительный анализ категорий «устойчивость финансовой системы региона» и «финансовая устойчивость региона» показал, что они не являются идентичными. Обращает на себя внимание, что авторы связывают финансовую устойчивость прежде всего с достаточностью финансовых ресурсов в регионе и их эффективным использованием в условиях изменения внешней и внутренней среды [3, с. $114 ; 4$, с. 172].

По нашему мнению, подобные трактовки следует рассматривать как количественную устойчивость. Между тем в трудах А.А. Богданова [5], а затем и в общей теории систем было доказано, что следует различать «количественную» и «структурную» устойчивость и что устойчивость системы определяется в большей степени устойчивостью структурных связей, а не элементов. Нам представляется, что при трактовке сущности понятия «устойчивость региональной фринансовой системы» акцент должен быть перенесен на системно-динамические свойства анализируемой системы: целостность, иерархичность, синергичность, открытость, способность к саморазвитию.

Такой подход отвечает концепции устойчивого развития, в соответствии с которой устойчивость становится важным драйвером ее динамики; переход системы от равновесия к волатильности возможен только в условиях неустойчивости, при этом структурно и функционально система должна оставаться устойчивой. Сопоставление данных категорий приводится в таблице 1.

Таблица 1 - Отличия понятий «финансовая устойчивость региона» и «устойчивость региональной финансовой системы» [6]

\begin{tabular}{|c|c|c|}
\hline Признаки сравнения & Финансовая устойчивость региона & $\begin{array}{c}\text { Устойчивость региональной } \\
\text { финансовой системы }\end{array}$ \\
\hline Содержание категории & фринансовая & социально-экономическая \\
\hline Концепция & общего экономического равновесия & устойчивого развития \\
\hline Предмет (ссрера) & $\begin{array}{l}\text { формирование и использование фи- } \\
\text { нансовых ресурсов региона }\end{array}$ & $\begin{array}{l}\text { системные признаки и структурно- } \\
\text { функциональные характеристики фри- } \\
\text { нансовых отношений в регионе }\end{array}$ \\
\hline Объект & $\begin{array}{l}\text { финансовое положение региона (фи- } \\
\text { нансовые ресурсы, их источники, ре- } \\
\text { зультат использования) }\end{array}$ & $\begin{array}{l}\text { интегральное свойство финнансовой си- } \\
\text { стемы как драйвера экономического ро- } \\
\text { ста и развития региона }\end{array}$ \\
\hline Субъекты управления & ЦБ РФ, Минфин в регионе и другие & $\begin{array}{l}\text { специальный орган для мониторинга и } \\
\text { системного управления в составе реги- } \\
\text { онального Министерства экономики и } \\
\text { инвестиционного развития }\end{array}$ \\
\hline Критерии оценки & $\begin{array}{l}\text { эфффективное фрункционирование и } \\
\text { развитие локальных ффинансовых } \\
\text { подсистем региона }\end{array}$ & $\begin{array}{l}\text { социально-экономический, бюджетно- } \\
\text { налоговый, инвестиционный, струк- } \\
\text { турно-фрункциональный }\end{array}$ \\
\hline Индикаторы оценки & $\begin{array}{l}\text { количественные и качественные по- } \\
\text { казатели различных финансовых под- } \\
\text { систем (банковская, бюджетно-нало- } \\
\text { говая, страховая и др.) }\end{array}$ & $\begin{array}{l}\text { критериальные показатели устойчиво- } \\
\text { сти финансовой системы региона, } \\
\text { сравнение с пороговыми значениями }\end{array}$ \\
\hline
\end{tabular}

В сравнительном анализе мы опирались на базовые признаки устойчивости экономических систем [7], концептуальные подходы к исследованию влияния финансовой системы на темпы и пропорции экономики [8], а также на исходные представления о роли региональной финансовой системы в развитии территории. В соответствии с авторской трактовкой [9, с. 85] финансовую систему региона необходимо рассматривать как единое образование, а не просто объединение различных (банки, бюджет) подсистем, хоть и взаимосвязанных между собой, как их реальное взаимодействие, нацеленное на эффективное и устойчивое развитие территории в интересах 
решения социальных и экономических задач. Финансовая система региона должна активно содействовать экономическому росту, стимулировать инновационную составляющую регионального развития. Именно этот аспект является определяющим в выборе приоритетов развития региональной финансовой системы. Главным звеном этого взаимодействия служит механизм инвестиционной активности, обеспечивающий рост всех видов инвестиций (производственных, фринансовых, социальных) и, следовательно, экономический рост.

На основе выполненного исследования можно предложить следующее определение: устойчивость финансовой системы региона - это способность региональной финансовой системы эффрективно выполнять свои социально-экономические функции в условиях возмущающих воздействий внешних и внутренних рисков изменяющейся финансово-экономической среды.

В условиях истощения традиционных источников экономического роста и сложной геополитической обстановки финансовая система страны в целом и региональные финансовые системы в частности столкнулись с новыми угрозами и вызовами.

В числе проблем, потенциально способных привести к негативным последствиям от глобализационных процессов во всех странах, исследователи выделяют [10, с. 79]:

- неравномерность распределения преимуществ от финансовой глобализации в разрезе отдельных отраслей национальной экономики,

- возможную деиндустриализацию национальных экономик,

- возможность перехода контроля над экономикой отдельных стран от их правительств в другие руки, в том числе к более сильным государствам, ТНК или международным организациям,

- возможную дестабилизацию фринансовой сферы, потенциальную региональную или глобальную нестабильность из-за взаимозависимости национальных экономик на мировом уровне.

Кроме глобальных вызовов, на развитие региональной финансовой системы огромное влияние оказывают изменения в экономической и финансовой политике, происходящие на национальном уровне. Приведем следующий пример.

В настоящее время одним из основных направлений развития финнансового рынка в РФ рассматривается создание трехуровневой банковской системы, предусматривающей новый вид кредитной организации - регионального банка и формирование группы федеральных банков. К числу региональных могут быть отнесены относительно небольшие кредитные организации с ограниченным кругом наиболее простых банковских операций [11].

Указанные реформы направлены на оздоровление финансового рынка, освобождение его от слабых и недобросовестных фринансовых институтов, упрощение банковского регулирования для небольших коммерческих банков. В то же время, несмотря на наличие положительного эффекта от таких мероприятий в глобальном масштабе, для региональных фринансовых систем последствия могут оказаться негативными, поскольку можно прогнозировать сокращение числа региональных банков, а значит, снижение конкуренции между банками и ужесточение требований к потенциальным заемщикам со стороны федеральных банков, которые традиционно более взвешенно подходят к принимаемым на себя рискам и предъявляют более высокие требования к качеству обеспечения по кредитам.

Снижение числа коммерческих банков и ослабление конкурентной позиции на региональном банковском рынке служат сигналами кризисного состояния региона как целостной развивающейся системы.

Региональная банковская система является одной из важнейших частей инфраструктуры рыночной экономики региона и его фринансовой системы, которую нельзя рассматривать в отрыве от других сфер региональной финансовой системы. Развитие региональной банковской системы и эффективное функционирование региональной экономики возможны только во взаимодействии. На региональном уровне необходимо создавать условия для результативного взаимодействия банков с реальным сектором экономики и активизации инвестиционного потенциала.

Поскольку основные параметры деятельности банков и кредитных организаций регионального уровня устанавливаются на уровне федерации, в результате она выводится из системы региональных экономических отношений, что может тормозить развитие регионального рынка банковского капитала. Дестабилизация регионального банковского сектора будет оказывать негативное влияние на финансовую устойчивость регионов, что приведет к снижению их самостоятельности.

Безусловно, региональные банки имеют ряд преимуществ, в числе которых концентрация на особенностях региональных и местных клиентов, понимание потребностей регионального бизнеса и т. п. Вместе с тем планируемое ограничение числа операций, выполняемых региональными банками, негативным образом скажется на банковском обслуживании, поскольку клиентам предпочтительнее получать все банковские услуги в одном финансовом учреждении. Это один из примеров взаимосвязи национальной финансовой системы и финансовой системы региона, один из фракторов, влияющих на устойчивость региональной финансовой системы. 
Не требует особых доказательств, что на состояние финансовой системы региона воздействует разнонаправленная совокупность фракторов (внешних и внутренних), которые непосредственно или опосредованно отражаются на ее устойчивости. Встает задача их выявления, классификации и группировки.

Мы разделяем точку зрения тех авторов, которые считают, что современная наука и практика настоятельно требуют обоснования и систематизации факторов, определяющих устойчивость национальной финансовой системы [12, с. 101]. В отношении региональных фринансовых систем эта проблема звучит не менее актуально.

В современной научной литературе при группировке и классификации фракторов, влияющих на состояние экономических систем, сложилось два направления исследования. Первое можно назвать эконометрическим, когда выявляются те факторы, которые могут быть количественно определены, измерены, смоделированы. Второе - функционально-стратегическое, в котором основное внимание акцентируется на глобализационных, политических, правовых, социально-экономических, административных, управленческих, реформационных и других процессах в экономике страны.

Представляется целесообразным синтезировать эти направления при классификации факторов и, опираясь на возможные фрормы проявления группировочных признаков, предложить следующие подходы к выявлению факторов устойчивости финансовой системы региона: содержательный, управленческий и аналитический (рис. 1).

\begin{tabular}{|c|c|c|}
\hline \multirow[b]{2}{*}{ Содержательный } & подходы & \multirow[b]{2}{*}{ Аналитический } \\
\hline & Управленческий & \\
\hline \multicolumn{3}{|c|}{ Признаки класса фракторов } \\
\hline $\begin{array}{c}\text { Целостность, открытость, } \\
\text { формы проявления, характер } \\
\text { функционирования }\end{array}$ & $\begin{array}{c}\text { Системность } \\
\text { и управляемость }\end{array}$ & $\begin{array}{c}\text { Инструменты анализа, } \\
\text { оценки и прогнозирования }\end{array}$ \\
\hline \multicolumn{3}{|c|}{ Факторы } \\
\hline Внутренние и внешние & Ситуационные & Валовой региональный продукт \\
\hline Глобальные и специфические & Интеграционные & Налоговый потенциал региона \\
\hline Социальные и экономические & Инвестиционные & Финансовый потенциал региона \\
\hline Правовые и политические & Институциональные & Инвестиционный потенциал региона \\
\hline Техногенные и природные & & Бюджетный потенциал региона \\
\hline $\begin{array}{c}\text { Социокультурные } \\
\text { и демографические }\end{array}$ & & $\begin{array}{c}\text { Потенциал реального сектора } \\
\text { экономики региона }\end{array}$ \\
\hline
\end{tabular}

\section{Рисунок 1 - Подходы к классификации факторов устойчивости финансовой системы региона [13]}

В соответствии с содержательным подходом финансовая система региона рассматривается как целостная и открытая система, имеющая свою внутреннюю организацию, свои противоречивые источники развития и внешние формы проявления и функционирующая в контакте с внешней средой. В соответствии с этим можно выделить следующие признаки группировки факторов: внутренние и внешние; глобальные и специфические; социальные и экономические; правовые и политические; техногенные и природные; социокультурные и демографические. Такой подход позволяет раскрыть роль и влияние различных факторов на формирование финансовых отношений, их содержание, качество решения финансовых задач, приоритеты развития и др.

При управленческом подходе главный признак классификации - это признак системности и управляемости. Выявляются те фракторы, которые поддаются воздействию с помощью мер экономической политики и могут быть использованы для ускорения финансового развития и укрепления устойчивости. В соответствии с этим можно выделить следующие факторы:

- ситуационные (приоритеты финансового развития фриксируются в государственных региональных программах и нормативных документах);

- интеграционные (механизмы регионального государственно-частного партнерства, инструменты государственной поддержки в сфере финансирования и кредитования отраслей и бизнеса); 
- инвестиционные (фринансовая грамотность населения, поддержка малых и средних предприятий, инвестиционная привлекательность региона);

- институциональные (информационная открытость фринансовых институтов, степень государственного участия в них, уровень концентрации банковского и реального секторов экономики, доступность фринансовых услуг населению).

В соответствии с аналитическим подходом фракторы рассматриваются как инструменты прогнозирования будущего развития финансовой системы региона (валовой региональный продукт, налоговый, финансовый, инвестиционный, бюджетный потенциал региона и др.). Аналитический подход позволяет количественно определить параметры, характеризующие жизнедеятельность региональной финансовой системы и ее финансовую базу.

В рамках аналитического подхода представляется целесообразным определить показатели, с помощью которых можно оценить уровень устойчивости региональной фринансовой системы, установить индикаторы и их пороговые значения, выход за пределы которых грозит разрушительными процессами и финансовой нестабильностью для региона.

В настоящее время апробированной индикативной базы для оценки и мониторинга устойчивости региональной финансовой системы не создано, не разработана и методика построения индикаторов. Отдельные аспекты этой проблемы представлены в публикациях [14], посвященных безопасности и устойчивости региона, что актуализирует задачу фрормирования адекватной системы индикаторов, позволяющих выполнить количественный и качественный анализ уровня устойчивости фринансовой системы региона.

Под экономическими индикаторами понимают величины, отражающие состояние экономики и позволяющие обнаружить тенденции развития, выявить угрозы, принять соответствующие решения.

На основе анализа специальных научных публикаций можно сделать вывод, что в качестве методических принципов для формирования системы индикаторов может быть использован подход к показателям, характеризующим устойчивость сложных социально-экономических объектов, разработанный в Международном институте устойчивого развития [15]. В соответствии с этим подходом:

- разработка показателей должна начинаться с определения ориентиров (критериев) оценки системы исходя из ее сущности и форм взаимодействия с внешней средой;

- устойчивость системы зависит от степени достижения базовых ориентиров;

- развитие системы будет сдерживаться базовыми ориентирами, которые находятся в состоянии минимального удовлетворения;

- особое внимание уделяется тем ориентирам, которые выступают в качестве сдерживающих фракторов;

- необходимо выбрать такие показатели, которые являются сигнальными и представляют наиболее уязвимые звенья системы.

В рамках авторской трактовки устойчивости региональной фринансовой системы выбраны следующие ориентиры (критерии) для формирования системы индикаторов: социально-экономический, бюджетно-налоговый, инвестиционный и структурно-функциональный.

Социально-экономический критерий является обобщающим, отражает в целом результаты развития экономики региона, в том числе производственно-хозяйственного комплекса, фринансовой сфреры, социальной среды. Основной целью развития и регулирования региональных фринансовых систем, по нашему мнению, является стимулирование экономического роста в регионах, который в свою очередь должен стать катализатором позитивных сдвигов по всех сферах фринансовой системы регионального уровня. Таким образом, этот критерий раскрывает мультипликативный эфффект взаимодействия фринансовой и экономической систем региона.

Бюджетно-налоговый критерий демонстрирует роль бюджетной и налоговой политики в регионе. Основным субъектом, формирующим фринансовые ресурсы, являются хозяйствующие субъекты, в то время как основным субъектом, оказывающим влияние на формирование финансовой системы региона и происходящие в ней процессы, являются органы государственной власти, создающие нормативную базу, механизмы и стимулы развития фринансового потенциала, государственно-частного партнерства, реального сектора экономики, задействуя в том числе имеющиеся в их распоряжении налоговые механизмы. Повышение эффрективности функционирования фринансовой системы региона во многом зависит от бюджетной системы региона, от объема фискальных полномочий органов государственной власти и местного самоуправления и от эфффективности и результативности расходования бюджетных средств, в том числе на фринансовую поддержку региональной экономики.

Инвестиционный критерий показывает уровень инвестиционной активности в регионе, роль фринансовых и нефинансовых организаций в этом процессе. Относительная фринансовая самостоятельность и независимость как атрибуты региональной финансовой системы непосредственно связаны со способностью системы самостоятельно генерировать необходимые объемы 
финансовых ресурсов и независимостью от внешних источников их поступлений, обеспечивая стабильную финансовую базу региона.

В данном аспекте необходимо определить объем инвестиционных финансовых ресурсов, которым располагает регион. Ответ на этот вопрос мог бы дать сводный финансовый баланс территории, основной задачей которого является определение объемов всех видов финансовых ресурсов (как централизованных, так и децентрализованных), созданных, поступивших и использованных в регионе. Однако в соответствии с действующей методологией, разработанной еще в советский период, в него не включаются доходы домашних хозяйств. Актуализируется проблема разработки новой системы показателей для территориального сводного финансового баланса, на основе которого можно анализировать достигнутый уровень мобилизации и использования финансовых ресурсов региона, выявления степени соответствия этого уровня потребностям развития региона.

Структурно-функциональный критерий должен раскрыть соотношение производственных и фринансовых процессов. Исследование показателей устойчивости региональной финансовой системы, относящихся, по мнению авторов, к данному критерию, позволит определить связи между отдельными звеньями финансовой системы региона, их функциональную устойчивость и эффрективность взаимодействия.

В соответствии с выбранными критериями встает задача определения показателей оценки. Применительно к устойчивости региональной финансовой системы в контексте авторской трактовки сущности этой категории требования к системе индикаторов, по нашему мнению, сводятся к следующим положениям:

1) индикаторы должны отражать свойства (признаки) устойчивости системы в целом, а не только ее отдельных подсистем;

2) демонстрировать причинно-следственные зависимости финансовой системы и экономики региона, отражать взаимосвязь с экономическим ростом;

3) выявлять динамику взаимодействия сфер и звеньев фринансовой системы и их влияние на социальные процессы;

4) определять базовые риски и угрозы для финансовой системы в региональном разрезе;

5) информация для расчетов должна быть доступной, содержаться в государственной статистике и официальной отчетности организаций; показатели должны быть обоснованы, подтверждены научными исследованиями.

По мнению авторов, этим требованиям отвечает следующая система показателей (рис. 2).

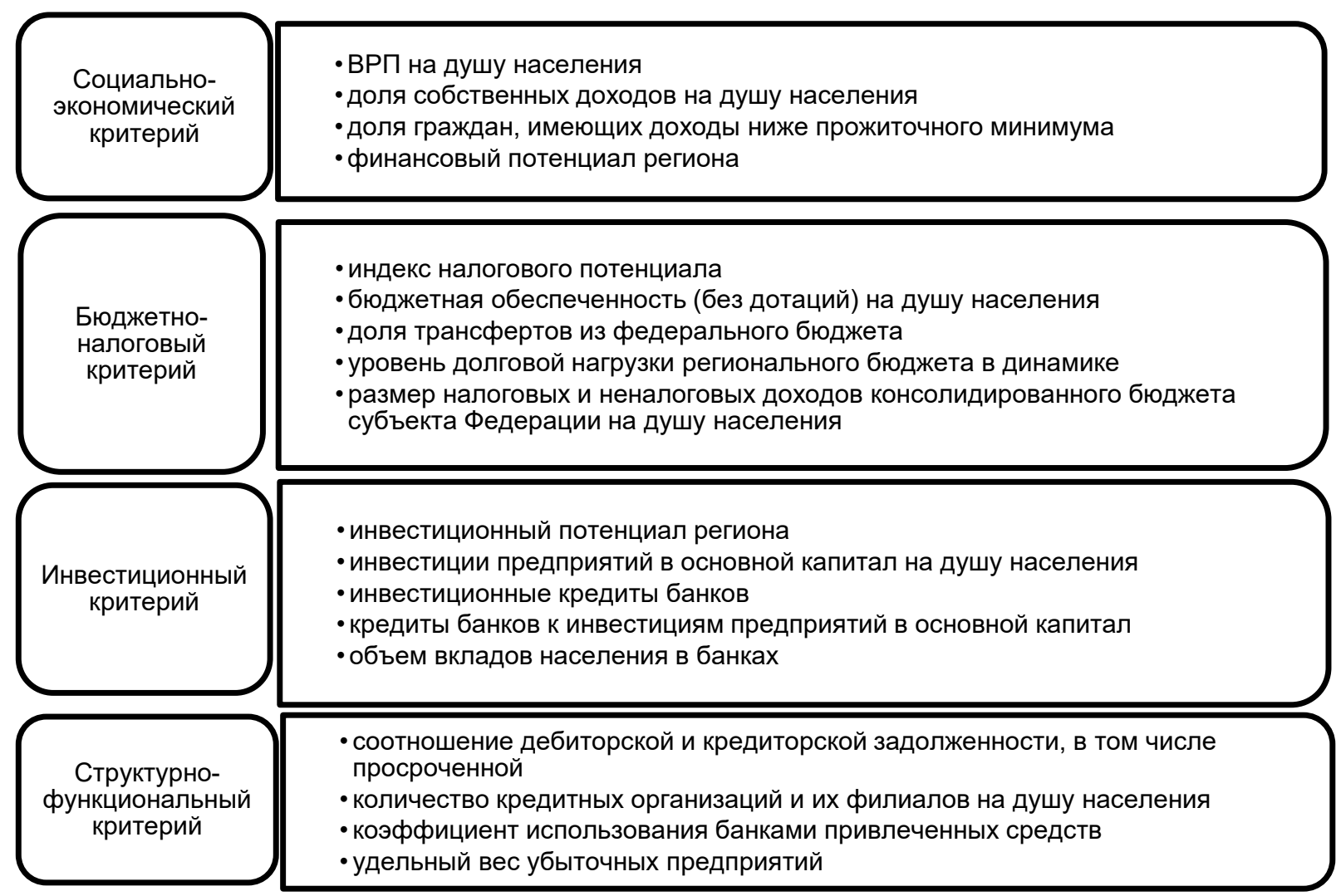

Рисунок 2 - Показатели устойчивости региональной финансовой системы 
Устойчивость региональной финансовой системы следует рассматривать как интегральное, динамическое свойство финансового сектора региона. Базовые критерии оценки и соответствующие индикаторы должны отражать инвестиционные и социально-экономические эфффекты взаимодействия с региональной экономикой.

Представленные показатели могут быть положены в основу индикативной системы, являющейся источником информации для соответствующих государственных органов власти о состоянии финансовой системы региона, для корректировки финансовой политики в регионе, определения эфффективных инвестиционных приоритетов, стимулирования новых фринансово-кредитных фрорм взаимодействия реального сектора экономики, кредитных организаций, населения. Однако для того, чтобы предлагаемая система индикаторов «работала», необходимо разработать методику определения и обоснования предельно-критических (пороговых) значений, отклонение от которых будет сигнализировать об активизации рисков и угроз для региональной финансовой системы. Для этого потребуются объемные научно-практические исследования по мониторингу в регионах, накоплению и обобщению информации, сравнительному анализу индикаторов. В дальнейшем индикаторы и их пороговые значения должны приобрести статус нормативных количественных параметров в программах социально-экономического развития регионов.

\section{Ссылки и примечания:}

1. Гарипов Ф.Н., Гарипова З.Ф. К вопросу финансовой устойчивости регионального развития // Экономика региона. 2010. № 1. С. 46-51; Паникин В.Е. Финансовая устойчивость и безопасность местных бюджетов // Вестник Волгоградского государственного университета. Серия 3: Экономика. Экология. 2009. № 1 (14). С. 133-137 ; Тетерятников К.С. Банковские и небанковские финансовые институты как основа устойчивой финансовой системы // Финансовая жизнь. 2015. № 3. С. 38-42 ; Ускова Т.В., Галухин А.В. Управление финансовой устойчивостью доходной базы бюджетов регионов: теоретико-методологические аспекты // Проблемы развития территории. 2015. Вып. 5 (78). C. $135-147$.

2. Эскиндаров М.А. Устойчивость финансовой системы России: индикаторы и критерии оценки // Вестник Финансового университета. 2012. № 2. С. 8-18.

3. Шевченко Л.М. Теоретический анализ устойчивости национальной финансовой системы // Вестник Саратовского государственного социально-экономического университета. 2012. № 2. С. 114-117.

4. Шимширт Н.Д. Анализ теоретических аспектов финансовой устойчивости регионов // Вестник Томского государственного университета. 2011. № 3 (175). С. 172-178.

5. Богданов А.А. Всеобщая организационная наука (тектология) : в 3 ч. 3-е изд., заново перераб. и доп. Л. ; М., 1925-1929.

6. Таблица 1 составлена авторами.

7. Белоцерковский О.М., Быстрай Г.П., Цибульский В.Р. Экономическая синергетика: вопросы устойчивости. Новосибирск, 2006 ; Михалев О.В. Экономическая устойчивость хозяйственных систем: методология и практика научных исследований и прикладного анализа. СПб., 2010. 200 с.

8. Ваниева М.Р. Влияние фринансового сектора на экономический рост: ретроспективный анализ // Ученые записки Крымского инженерно-педагогического университета. 2015. № 1. С. 28-35; Игонина Л.Л. Финансовое развитие и экономический рост // Вестник Финансового университета. 2016. № 1. C. 111-120 ; Greenwood R., Scharfstein D. The growth of modern finance [Электронный ресурc]. URL: http://www.people.hbs.edu/dscharfstein/growth_of_modern_finance.pdf (дата обращения: 15.10.2016) ; Merton R.C., Bodie Z.A. Conceptual framework for analyzing the financial environment. The global financial system: a functional perspective / eds.: D. B. Crane [et al.]. Boston, 1995. P. 3-31.

9. Зотова А.И., Кириченко М.В. Финансовая система региона: структурно-функциональный аспект // Современная наука: актуальные проблемы теории и практики. Серия: Экономика и право. 2015. № 11-12. С. 82-86.

10. Шевченко Л.М. Финансовая глобализация и риски утраты устойчивости национальной финансовой системы // Вестник Тамбовского государственного университета. Серия: Гуманитарные науки. 2012. № 7 (111). С. $79-83$.

11. Выступление Председателя Банка России Эльвиры Набиуллиной на XXV Международном фринансовом конгрессе 30 июня 2016 г. [Электронный pecypc]. URL: http://cbr.ru/press/print.aspx?file=press_centre/nabiullina_160630.htm\&pid=st\&sid=itm_15798 (дата обращения: 03.10.2016).

12. Шевченко Л.М. Факторы, определяющие устойчивость национальной финансовой системы // Вестник Саратовского государственного социально-экономического университета. 2013. № 2 (46). С. 101-105.

13. Рисунки 1 и 2 составлены авторами.

14. Ахметов Р.P. Проблемы методики оценки устойчивости финансовой системы региона // Региональная экономика: теория и практика. 2010. № 25 (160). С. 62-67 ; Духовенко В.С. Финансовая система региона: принципы фрормирования и развития // Фундаментальные исследования. 2014. № 2. С. 2388-2392 ; Казаков В.В. Современные проблемы развития и направления реформирования региональных финансовых систем // Вестник Томского государственного университета. 2013. № 373. С. 141-146 ; Меньщикова В.И., Синополец Н.В. Система индикаторов оценки устойчивого развития экономики региона // Социально-экономические явления и процессы. 2011. № 5-6 (027-028). С. 155-160.

15. Боссель X. Показатели устойчивого развития: теория, метод, практическое использование : отчет, представленный на рассмотрение Балатонской группы : пер. с англ. Тюмень, 2001.

\section{References}

Akhmetov, RR 2010, 'Problems of methodology for assessing the stability of the regional financial system', Regional'naya ekonomika: teoriya i praktika, no. 25 (160), pp. 62-67, (in Russian). sian).

Belotserkovsky, OM, Bystray, GP \& Tsibulsky, VR 2006, Economic synergetics: sustainability issues, Novosibirsk, (in Russian).

Bogdanov, AA 1925-1929, The general organizational science (tectology), in 3 parts, 3rd ed., Leningrad, Moscow, (in Rus- 
Bossel, H 2001, Indicators for sustainable development: theory, method, applications: a Report to the Balaton Group, Tyumen, (in Russian).

Dukhovenko, VS 2014, 'The financial system of the region: the principles of formation and development', Fundamental'nyye issledovaniya, no. 2, pp. 2388-2392, (in Russian).

Eskindarov, MA 2012, 'Sustainability of the Russian financial system: indicators and evaluation criteria', Vestnik Finansovogo universiteta, no. 2, pp. 8-18, (in Russian).

Garipov, FN \& Garipova, ZF 2010, 'Concerning the issue of financial sustainability of the regional development', Ekonomika regiona, no. 1, pp. 46-51, (in Russian).

Greenwood, R \& Scharfstein, D 2016, The growth of modern finance, viewed 15 October 2016, <http://www.people.hbs.edu/dscharfstein/growth_of_modern_finance.pdf>, https://doi.org/10.2139/ssrn.2162179.

Igonina, LL 2016, 'The financial development and economic growth', Vestnik Finansovogo universiteta, no. 1, pp. 111-120, (in Russian).

Kazakov, VV 2013, 'Modern problems of development and directions of reforming regional financial systems', Vestnik Tomskogo gosudarstvennogo universiteta, no. 373, pp. 141-146, (in Russian).

Menshchikova, VI \& Sinopolets, NV 2011, 'The system of indicators for assessing the sustainable development of the regional economy', Sotsial'no-ekonomicheskiye yavleniya i protsessy, no. 5-6 (027-028), pp. 155-160, (in Russian).

Merton, RC, Bodie, ZA \& Crane, DB (et al.) (eds.) 1995, Conceptual framework for analyzing the financial environment. The global financial system: a functional perspective, Boston, pp. 3-31.

Mikhalev, OV 2010, Economic sustainability of economic systems: methodology and practice of scientific research and applied analysis, St.-Petersburg, 200 p., (in Russian).

Panikin, VE 2009, 'Financial stability and local budgets security', Vestnik Volgogradskogo gosudarstvennogo universiteta. Seriya 3: Ekonomika. Ekologiya, no. 1 (14), pp. 133-137, (in Russian).

Shevchenko, LM 2012a, 'Financial globalization and risks of stability loss of the national financial system', Vestnik Tambovskogo gosudarstvennogo universiteta. Seriya: Gumanitarnyye nauki, no. 7 (111), pp. 79-83, (in Russian).

Shevchenko, LM 2012b, 'Theoretical analysis of the stability of the national financial system', Vestnik Saratovskogo gosudarstvennogo sotsial'no-ekonomicheskogo universiteta, no. 2, pp. 114-117, (in Russian).

Shevchenko, LM 2013, 'Factors determining the stability of the national financial system', Vestnik Saratovskogo gosudarstvennogo sotsial'no-ekonomicheskogo universiteta, no. 2 (46), pp. 101-105, (in Russian).

Shimshirt, ND 2011, 'The analysis of the theoretical aspects of the regional financial stability', Vestnik Tomskogo gosudarstvennogo universiteta, no. 3 (175), pp. 172-178, (in Russian).

Speech of the Chairman of the Bank of Russia Elvira Nabiullina at the XXV International Financial Congress on June 30, 2016 2016, viewed 03 October 2016, <http://cbr.ru/press/print.aspx?file=press_centre/nabiullina_160630.htm\&pid=st\&sid=itm_15798>, (in Russian).

Teteryatnikov, KS 2015, 'Banking and non-banking financial institutions as the basis of a stable financial system', Finansovaya zhizn', no. 3, pp. 38-42, (in Russian).

Uskova, TV \& Galukhin, AV 2015, 'Financial stability management of the revenue base of the regional budgets: theoretical and methodological aspects', Problemy razvitiya territorii, vol. 5 (78), pp. 135-147, (in Russian).

Vanieva, MR 2015, 'The influence of the financial sector on economic growth: a retrospective analysis', Uchenyye zapiski Krymskogo inzhenerno-pedagogicheskogo universiteta, no. 1, pp. 28-35, (in Russian).

Zotova, Al \& Kirichenko, MV 2015, 'The financial system of the region: the structural and functional aspect', Sovremennaya nauka: aktual'nyye problemy teorii i praktiki. Seriya: Ekonomika i pravo, no. 11-12, pp. 82-86, (in Russian). 